\title{
Pediatric Tracheostomy at a Tertiary Healthcare Institution: A Retrospective Study Focused on Outcomes
}

\author{
Ahmet Yukkaldıran $^{1}$ (D) Ahmet Doblan $^{2}$ (D) \\ Received: 15 June 2020/Accepted: 24 August 2020/Published online: 31 August 2020 \\ (C) Association of Otolaryngologists of India 2020
}

\begin{abstract}
The aim of this study was to retrospectively evaluate all pediatric tracheotomies that had been performed at Sanliurfa Training and Research Hospital From September 2016 to July 2019. A retrospective study was performed on pediatric patients who had undergone tracheostomy during the three-year study period. Patient data were reviewed for the following variables: age, gender, age at the time of tracheostomy, primary indication for tracheostomy, length of stay in intensive care unit before and after tracheostomy, complications, mortality and cause of death. The primary indication for tracheostomy was categorized into 4 separate groups: congenital disease, traumatic injury, prolonged intubation and other causes. The study group consisted of 138 children. Seventy-one $(51.4 \%)$ of the children were male, 67 (48.6\%) were female and the mean age of tracheostomy was $13.30(0.03-192.27)$ months, and $44.2 \%$ were younger than 1 year when tracheotomy was performed. The median age at the time of tracheostomy was highest in children who underwent tracheostomy for traumatic injury. The indication for tracheostomy was prolonged intubation in $73.2 \%$ of the children. Complications were observed in 13 (9\%) children; bleeding (69.2\%) was the most common. Complications were most frequent in children who underwent tracheostomy for prolonged intubation. The overall mortality ratewas $30.4 \%$ with cardiac arrest being the most common cause. At our center, the most common indication
\end{abstract}

Ahmet Yukkaldıran

ayukkaldiran@gmail.com

1 Department of Otorhinolaryngology, Sanliurfa Training and Research Hospital, Sanliurfa, Turkey

2 Department of Otorhinolaryngology, SBÜ Mehmet Akif İnan Training and Research Hospital, Sanliurfa, Turkey for tracheostomy in children was long-term intubation, possibly due to our center being a tertiary healthcare institute. Bleeding was the most common complication, while cardiac arrest was the most common cause of death.

Keywords Tracheostomy · Prolonged intubation · Airway obstruction - Pediatric intensive care

\section{Introduction}

In recent years, the indications and complications of tracheostomy and the epidemiological profile of recipients have evolved [1]. The best examples of these changes may be the increased rate of vaccination for croup, diphtheria and epiglottitis, as well as the ever-decreasing rate of patients undergoing tracheostomy for these reasons [2]. Other obstructive indications include craniofacial malformations, subglottic stenosis, tracheomalacia, and tumors that block the airway. In the past, the most common indication for tracheostomy was airway obstruction [2, 3]. In addition to the need for endotracheal intubation due to pulmonary or cardiac malformations, chronic pulmonary insufficiency, neurological disorders and cervical trauma, the developments in advanced life support systems and experience in this field has ledto an increased survival rate among children, but this has also madeprolonged endotracheal intubation and mechanical ventilation a much more common occurrence. Furthermore, with the advances in neonatal care, babies can now stay on long-term ventilator support for weeks or even months [4]. Tracheostomies facilitate pulmonary clearance in such patients and reduce chronic laryngotracheal lesions due to long-term intubation [2]. In recent years, the most common indications for 
tracheostomy in the pediatric population were reported to be long-term intubation and upper airway obstruction [4].

Tracheostomy is often a life-saving intervention, but may also cause serious complications. As the age of pediatric patients decreases, the risk of complications increases $[2,3,5,6]$. Mortality rates in children have been shown to increasewith tracheostomies performed in emergencies and seriously ill patients. In children, the most common cause of death associated with tracheostomy is tube obstruction followed by incorrect placement of the tube and accidental decannulation [4].

Features associated with the use of pediatric tracheostomy (indications, complications, age etc.), in Turkey have significantly changed over time [7-11]. Understanding these features is important for proper management of patients. In Turkey, detailed research studies evaluating the epidemiology of pediatric tracheostomy are few and far between. The aim of this study was to retrospectively evaluate all pediatric tracheotomies that had been performed in Sanliurfa Training and Research Hospital from September 2016 to July 2019.

\section{Materials and Methods}

A retrospective study was performed on pediatric patients who underwent tracheostomy during the 3 year study period (from September 2016 to July 2019) at Sanliurfa Education and Research Hospital. Sanliurfa Education and Research Hospital is a tertiary referral center in the southeastern region of Turkey, and receives high complexity patients.

Ethics committee approval and necessary administrative permissions were obtained in accordance with the Helsinki Declaration.

Our hospital was established 1.5 years ago with the merger of the only maternity hospital and pediatric hospital in the city. There is a 162-bed pediatric and neonatal intensive care unit in our hospital. The number of pediatric and neonatal intensive care unit patients per year is around 4500. Due to the high rate of consanguineous marriages, high fertility rate, increase in the birth rate of Syrian refugees and insufficient follow-up during the birth process, the birth rate of risky babies is increasing. Only in our hospital, there are approximately 35,000 thousand births in a year and $40 \%$ of these births are Syrian refugee babies.

\section{Inclusion Criteria and Measurements}

Patients were excluded if they were older than 18 years of age at the time of tracheostomy or if they had incomplete medical records. Patients' data were reviewed for the following variables: age, gender, age at the time of tracheostomy, primary indication for tracheostomy, length of stay in intensive care unit before and after tracheostomy, complications, comorbidities, mortality, and cause of death.

The primary indication for tracheostomy was categorized into four separate groups: airway obstruction due to congenital disease, airway obstruction due to traumatic accident, airway obstruction due to other reasons (angioedema, postoperative complications, infection, etc.), and prolonged intubation.

\section{Procedures}

All pediatric tracheostomies are performed under general anesthesia. During tracheostomy, a standard tracheostomy procedure is used, including a horizontal skin incision and a vertical trachea incision. Stay sutures are placed on both sides of the tracheal incision. Stomal maturation sutures are inserted from the trachea to the skin. The tracheostomy tube is then inserted. After tracheostomy, all children are admitted to the pediatric intensive care unit (PICU). Decanulation was performed successfully in 17 patients. Decanulation was performed in 9 patients in the prolonged mechanical ventilation group, 5 patients in the congenital disorders group with upper airway obstruction, 3 patients in the traumatic group with upper airway obstruction.

\section{Statistical Analysis}

All analyses performed on SPSS v15. In the evaluation of descriptive data, number (n), percentage (\%), mean, standard deviation (SD), median, minimum (min) and maximum (max) values were used. For the normalty check Shapiro-Wilk test was used. Assessment of the continuos variables made by using Kruskal-Wallis test. Categorical variables analyzed by using Chi square test. $P<0.05$ values accepted as statistically significant results.

\section{Results}

The study group consisted of 138 children. Seventy-one (51.4\%) of the children were male, $67(48.6 \%)$ were female and the mean age of tracheostomy was 13.30 (0.03-192.27) months. The most common indication for tracheostomy was prolonged intubation $(73.2 \%)$ which was followed by airway obstruction due to congenital diseases (15.9\%), airway obstruction due to traumatic injury (6.5\%), airway obstruction due to other reasons $(4.3 \%)$. When the children undergoing tracheosomy were examined according to age groups, tracheostomy was found to be most commonly performed in children under 1 year of age and $44.2 \%$ were 
younger than 1 year when tracheostomy was performed (see Fig. 1).

Most of the patients who underwent tracheostomy for long-term intubation had neurological disease. The most common indication for tracheostomy in patients with airway stenosis due to congenital diseases was laryngeal tracheal malacia. Most of the patients were born in the term and subsequently indicated for intensive care unit because of chronic diseases. Preterm patients were mostly in the congenital diseases group with upper respiratory tract obstruction. Information about the indications of tracheostomy is given in Table 1 .

Complications were observed in 13 (9\%) children who underwent tracheostomy. After tracheostomy, bleeding (53.8\% in early period, $15.4 \%$ in late period and $69.2 \%$ in total) was the most common complication in children. Bleeding in the early period was bleeding in the form of infiltration. Bleeding stopped spontaneously with printed dressing. Late bleeding was more severe. Bleeding of one patient was controlled by bedside cauterization, while the bleeding of one patient was controlled by connecting the vascular structure under operating room conditions. The majority of the complications occurred in the first 7 days (early period). Complications were most commonly seen in children undergoing tracheostomy for prolonged intubation. Complications observed in the prolonged intubation group were as follows: Early bleeding was observed in 2 patients with neuromuscular disease and 3 patients with metabolic disease. Cannula obstruction was observed in 1 patient with neurological disease. Pneumothorax was observed in one patient with neurological disease on the second postoperative day. Late bleeding was observed in one patient with neurological disease on the 22nd postoperative day. The complications observed in the tracheostomy group due to congenital upper respiratory tract obstruction are as follows: Cannula dislocation was observed in the patient who underwent emergency tracheotomy due to congenital giant cystic hygroma. Cardiac arrest was observed in the premature baby with tracheal atresia, stenosis and cyanotic heart disease. No complication was observed in tracheostomy patients due to traumatic upper respiratory tract obstruction. Two patients who underwent tracheotomy due to other causes of upper airway obstruction had early bleeding on the second postoperative day and late bleeding on the 12 th postoperative day. Table 2 presents the frequency of various complications observed in our patients.

After tracheostomy, the mortality rate in children was $30.4 \%$. There was no direct death due to tracheotomy.

The most common causes of death were cardiac arrest, pneumonia and sepsis (Table 3).

Complications were most frequent in children who underwent tracheostomy for prolonged intubation (Table 4). The median age at the time of tracheostomy was highest in children who underwent tracheostomy for traumatic injury. The group with the longest duration of ICU stay before tracheostomy was found to have tracheostomy due to prolonged intubation. The group with the longest period of stay in the ICU after tracheostomy was found to have undergone tracheostomy due to traumatic injury. Table 4 presents characteristics and outcomes of patients who underwent tracheotomy by indication.

\section{Discussion}

Over the years, the indications of tracheostomy and the features of pediatric tracheostomy recipients have shown significant changes in Turkey, similar to global trends. In the past, the most common indication for tracheostomy was airway obstruction, often due to infectious diseases [12]. However, today, the most common indications for tracheostomy in the pediatricare long-term intubation and upper airway obstruction due to various causes [2, 5, 13]. In this study, we found that the most common indication for tracheostomy in children was long-term intubation $(73.2 \%)$.
Fig. 1 Distribution of children according to age at the time of tracheostomy

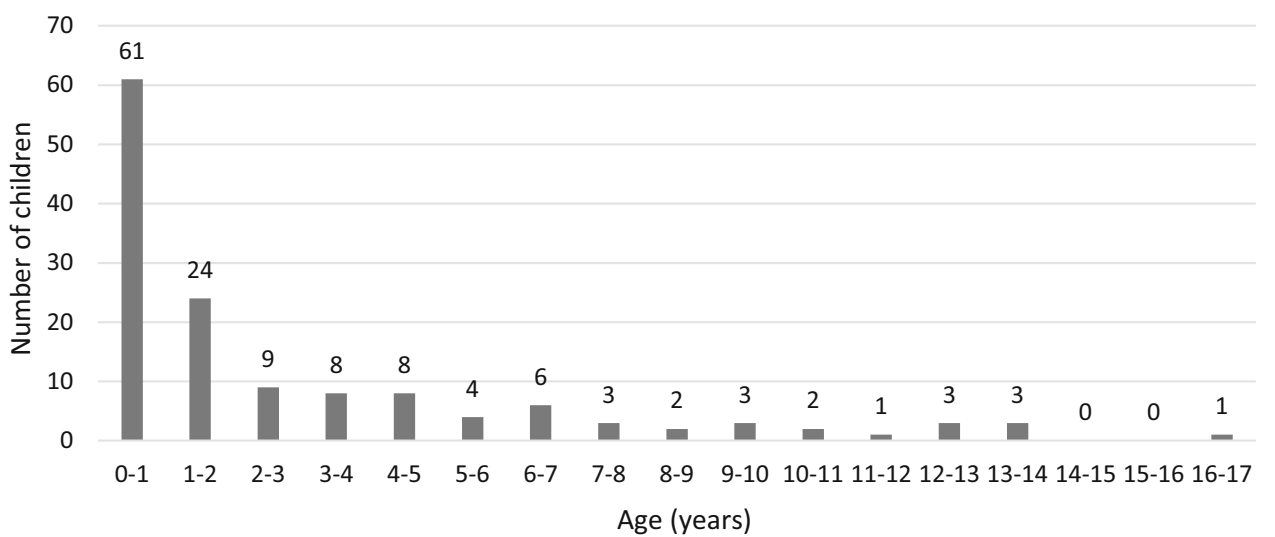


Table 1 Indications of tracheostomy

\begin{tabular}{lc}
\hline & $\mathrm{n}(\%)$ \\
\hline Prolonged intubation & $101(73.18)$ \\
Neuromuscular disease & $30(21.7)$ \\
Neurological diseases & $51(37.0)$ \\
Metabolic diseases & $10(7.2)$ \\
Muscular diseases & $9(6.5)$ \\
Bronchopulmonary dysplasia & $1(0.7)$ \\
Airway obstruction due to congenital disease & $22(15.9)$ \\
Bilateral vocal cord paralysis & $2(1.5)$ \\
Pierre Robin syndrome & $3(2.2)$ \\
Subglottic stenosis & $1(0.7)$ \\
Subglottic web & $1(0.7)$ \\
Tracheal atresia, stenosis & $2(1.5)$ \\
Coexistence of tracheocephagial cleft and trachea atresia & $1(0.7)$ \\
Laryngo tracheal malacia & $8(5.8)$ \\
Head and neck tumors congenital cystic hygroma) & $3(2.2)$ \\
Congenital intralarengeal saccular cyst & $1(0.7)$ \\
Airway obstruction due to traumatic injury & $9(6.5)$ \\
Retropharyngeal area hematoma after cervical spine & $1(0.7)$ \\
injury & \\
Laryngeal edema developing after burn & $1(0.7)$ \\
Laryngeal damage after caustic ingestion & $2(1.5)$ \\
Laryngeal trauma after entanglement & $1(0.7)$ \\
Laryngeal injury after traffic accident & $1(0.7)$ \\
Maxillofacial trauma & $1(0.7)$ \\
Open injury of larynx after eruption & $2(1.5)$ \\
Airway obstruction due to other reasons & $6(4.4)$ \\
\hline &
\end{tabular}

Table 2 Complications after tracheostomy

\begin{tabular}{lc}
\hline Complications & $\mathrm{n}(\%)$ \\
\hline Early complications (0-7 days) & $11(84.6)$ \\
Bleeding & $7(53.8)$ \\
Dislocation of the cannula & $1(7.7)$ \\
Cannula obstruction & $1(7.7)$ \\
Cardiac arrest & $1(7.7)$ \\
Pneumothorax & $1(7.7)$ \\
Late complications (after 7 days) & $2(15.4)$ \\
Bleeding & $2(15.4)$ \\
Total & $13(100.0)$
\end{tabular}

According to an extensive study of tracheostomies performed in Canada between 1982 and 2011, upper airway obstruction was reported as the most common indication for tracheostomy (33\%) [14], and this result was supported in studies performed between 1990-2009 [15], 1990-2007 [16], 1987-2003 [17], and 1990-1999 [18]. Other studies
Table 3 Causes of death after tracheostomy

\begin{tabular}{ll}
\hline Causes of death & $\mathrm{n}(\%)$ \\
\hline Cardiac arrest & $11(26.2)$ \\
Pneumonia & $8(19.0)$ \\
Sepsis & $6(14.3)$ \\
Intracranial hemorrhage & $5(11.9)$ \\
Congenital anomaly & $4(9.5)$ \\
Multiple organ failure & $3(7.1)$ \\
Respiratory arrest & $2(4.8)$ \\
West syndrome & $1(2.4)$ \\
Kidney failure & $1(2.4)$ \\
Brain tumor & $1(2.4)$ \\
Total & $42(100.0)$ \\
\hline
\end{tabular}

indicate that the most common indication for tracheostomy is cardiopulmonary disease (34\%) [19], congenital neurological disease (33\%) [20], neurological disorders [13, 21], and congenital malformations (44\%) [12]. However, in more recent studies investigating children with tracheostomy, themost frequent indication was long-term intubation; as shown by studies performed between 2001-2012 (20\%) [2], 2008-2009 (62.6\%) [22], and 2010-2018 (38.4\%) [23]. However, interestingly, one study reported that although the most common cause was long-term intubation between 2000 and 2005, this was not the case in their patients between 2006 and 2011, in which the most common cause was upper airway obstruction [24].

In Turkey, Tolunay et al. [11] and Akcan et al. [8] reported the most common indication for pediatric tracheostomy as neurological disorders. However, Özmen et al., in their exhaustive evaluation of patients, found that airway obstruction was the most frequent indication between 1968 and 1990, while long-term intubation had become the most common indication in the 1990-2005 time period [9]. This change in characteristics resembles worldwide trends, and is supported by various other studies performed between 2000-2006 and 2007-2010 [7, 10].

Taken together, it seems that the most common indication of tracheostomy before the year 2000 is (upper) airway obstruction. In the following years, the most common indication is generally reported as long-term intubation. The results of our study are consistent with results both in Turkey and the World and it is rather apparent that, today, the most common indication for tracheostomy is long-term intubation. In regard to other results, there may be many reasons for the differences, including differences in definitions, local disease characteristics, hospital characteristics that influence patient referrals, and also the secondary/ tertiary nature of each institute. 
Table 4 Characteristics and outcomes of patients who underwent tracheotomy by indication

\begin{tabular}{|c|c|c|c|c|c|}
\hline & $\begin{array}{l}\text { Prolonged } \\
\text { intubation }\end{array}$ & $\begin{array}{l}\text { Airway obstruction due to } \\
\text { congenital disease }\end{array}$ & $\begin{array}{l}\text { Airway obstruction due to } \\
\text { traumatic injury }\end{array}$ & $\begin{array}{l}\text { Airway obstruction due } \\
\text { to other reasons }\end{array}$ & $p$ value \\
\hline \multicolumn{6}{|l|}{ Gender } \\
\hline Male & $53(74.6 \%)$ & $8(11.3 \%)$ & $8(11.3 \%)$ & $2(2.8 \%)$ & \multirow[t]{2}{*}{0.048} \\
\hline Female & $48(71.6 \%)$ & $14(20.9 \%)$ & $1(1.5 \%)$ & $4(6.0 \%)$ & \\
\hline \multicolumn{6}{|l|}{ Complication } \\
\hline Present & $8(61.5 \%)$ & $2(15.4 \%)$ & $0(0.0 \%)$ & $3(23.1 \%)$ & \multirow[t]{2}{*}{0.005} \\
\hline Absent & $93(74.4 \%)$ & $20(16.0 \%)$ & $9(7.2 \%)$ & $3(2.4 \%)$ & \\
\hline \multicolumn{6}{|l|}{ Mortality } \\
\hline Present & $30(71.4 \%)$ & $10(23.8 \%)$ & $1(2.4 \%)$ & $1(2.4 \%)$ & \multirow[t]{2}{*}{0.213} \\
\hline Absent & $71(74.0 \%)$ & $12(12.5 \%)$ & $8(8.3 \%)$ & $5(5.2 \%)$ & \\
\hline Age at tracheostomy (days) & $\begin{array}{l}411 \\
\quad(48-4725)\end{array}$ & $65(1-5768)$ & $1094(74-4341)$ & $697(75-2520)$ & $<0.001$ \\
\hline $\begin{array}{l}\text { Length of stay in ICU before } \\
\text { tracheostomy (days) }\end{array}$ & $31(9-204)$ & $15(0-66)$ & $24(14-59)$ & $17(1-45)$ & $<0.001$ \\
\hline $\begin{array}{l}\text { Length of stay in ICU after } \\
\text { tracheostomy (days) }\end{array}$ & $30(1-130)$ & $10(1-120)$ & $66(12--236)$ & $32(12-83)$ & $<0.001$ \\
\hline
\end{tabular}

The majority of the tracheostomy cases in this study were performed on boys $(51.4 \%)$. Similar results (55.8-64.0\%) have been reported in many other studies $[2,3,9,10,18,20,23]$, with the exception of few in which female gender was more frequent. For instance, Tolunay et al. [11] reported that $52.8 \%$ of their cases were female.

According to the results of various studies, the majority of children undergoing tracheostomy have been reported to be under 1 year of age [2, 3, 8, 10, 13-15, 20, 22, 23]. In our study, different to the literature, the majority of children with tracheostomy $(55.8 \%)$ were found to be over 1 year of age.

In the study, the median age was highest among patients who underwent tracheostomy due to traumatic accidents. Similar results have been reported in previous studies $[19,25]$. Traumatic injuries are caused by head and neck injuries after caustic drinking, falling and traffic accidents. It is not surprising that these traumatic accidents occur at an older age with an increase in physical activity. Tracheostomy is a treatment with severe side effects that may be common depending on the patients condition. Tissue traumatization, damage to the laryngeal or tracheal mucosa, and forced insertion of the cannula cause early complications (pneumomediastinum, pneumothorax, bleeding, wound complications, cannula insertion), and late complications (tracheal stenosis, laryngeal stenosis, cannula re-insertion) [12]. The incidence of complications after tracheostomy in children was $9 \%$ and the most common complication was bleeding $(69.2 \%)$ in the current study. When compared with regard to indications, the highest complication rate was found in children with long- term intubation. The incidence of complications has been reported to range from 17 to $77 \%$ in other studies [8-11, 13, 14, 17, 18, 22]. Although some studies have reported that the most common complication is pneumothorax [3], and accidental decanulation [14], the majority of studies in the literature have reported peristomal granulation as the most common complication [7-10, 13]. According to a review of 47 studies by Dal'Astra et al., the most common complication was peristomal granulation [1]. The complication rate we found in this study was rather low compared to other studies in the literature. Reducing the complications of tracheostomy is important for reducing both mortality and morbidity and length of hospital stay. For this purpose, it should be aimed to minimize tissue damage with optimal anatomical orientation during tracheostomy. It is clear that the operation should be performed by an experienced surgeon in order to reduce tissue damage. In the event of a possible complication, it is important to recognize and treat the complications quickly in order to prevent devastating consequences.

It has been reported that morbidity and mortality rates in pediatric tracheostomies are 2-3 times higher than in adult patients [12]. In this study, the incidence of mortality after tracheostomy was $30.4 \%$ and the most common cause of death was cardiac arrest. The frequency of mortality after tracheostomy has been reported between 2.2 and $59 \%$ in other studies [1-3, 7-10, 13, 20, 22, 23, 26, 27]. According to the study of Douglas et al. [2], the most common cause of death after tracheostomy is lung infection and cardiac complications, while Roberts et al. reports respiratory 
disorders as the most frequent culprit [23]. The mortality rate in our study was relatively high compared to the majority of studies. The fact that ours is a tertiary referral hospital to which patients in critical condition and severe problems are accepted, may have contributed to this results. Furthermore, due to the retrospective nature of the study, it was impossible to ascertain whether deaths were directly associated with tracheostomy or not. This is a limitation as death reports may vary according to the issuer and therefore cannot be standardized.

\section{Conclusion}

In our study, most of the children who underwent tracheostomy were males and older than 1 year of age. The most common indication for tracheostomy in children was long-term intubation, bleeding was the most common complication, and cardiac arrest was the most common cause of death. The median age of children who underwent tracheostomy due to trauma was higher than other indications. Further studies are needed to reveal the features of pediatric tracheostomy with stronger evidence.

Acknowledgements We thank Doctor Burak Erdene for her contributions.

Funding The authors declared that this study had received no financial support

\section{Compliance with Ethical Standards}

Conflict of interest No conflict of interest was declared by the authors.

\section{References}

1. Dal'Astra AP, Quirino AV, Caixêta JA et al (2017) Tracheostomy in childhood: review of the literature on complications and mortality over the last three decades. Braz J Otorhinolaryngol 83:207-214

2. Douglas CM, Poole-Cowley J, Morrissey S et al (2015) Paediatric tracheostomy-an 11 year experience at a Scottish paediatric tertiary referral centre. Int $\mathrm{J}$ Pediatr Otorhinolaryngol 79:1673-1676

3. Schweiger C, Manica D, Becker CF et al (2017) Tracheostomy in children: a ten-year experience from a tertiary center in southern Brazil. Braz J Otorhinolaryngol 83:627-632

4. Watters KF (2017) Tracheostomy in infants and children. Respir Care 62:799-825

5. Parrilla C, Scarano E, Guidi ML et al (2007) Current trends in paediatric tracheostomies. Int $\mathrm{J}$ Pediatr Otorhinolaryngol 7:1563-1567

6. Gilmore BB Jr, Mickelson SA (1986) Pediatric tracheotomy. Controversies in management. Otolaryngol Clin $\mathrm{N}$ Am 19:141-151
7. Karapinar B, Arslan MT, Ozcan C (2008) Pediatric bedside tracheostomy in the pediatric intensive care unit: six-year experience. Turk J Pediatr 50:366-372

8. Akcan FA, Dündar Y, Uluat A et al (2018) Pediatric tracheotomies: a 5-year experience in 152 children. ENT Updates 8:71-78

9. Ozmen S, Ozmen OA, Unal OF (2009) Pediatric tracheotomies: a 37-year experience in 282 children. Int J Pediatr Otorhinolaryngol 73:959-961

10. Atmaca S, Bayraktar C, Aşilioğlu N et al (2011) Pediatric tracheotomy: 3-year experience at a tertiary care center with 54 children. Turk J Pediatr 53:537-540

11. Tolunay I, Yıldızdaş RD, Horoz OO et al (2015) An assesment of pediatric tracheostomy in a pediatric intensive care unit. CAYD 2:60-64

12. Kremer B, Botos-Kremer AI, Eckel HE et al (2002) Indications, complications, and surgical techniques for pediatric tracheostomies-an update. J Pediatr Surg 37:1556-1562

13. Carron JD, Derkay CS, Strope GL et al (2000) Pediatric tracheotomies: changing indications and outcomes. Laryngoscope 110:1099-1104

14. Ogilvie LN, Kozak JK, Chiu S et al (2014) Changes in pediatric tracheostomy 1982-2011: a Canadian tertiary children's hospital review. J Pediatr Surg 49:1549-1553

15. de Trey L, Niedermann E, Ghelfi D et al (2013) Pediatric tracheotomy: a 30-year experience. J Pediatr Surg 48:1470-1475

16. Al-Samri M, Mitchell I, Drummond DS et al (2010) Tracheostomy in children: a population based experience over 17 years. Pediatr Pulmonol 45:487-493

17. Mahadevan M, Barber C, Salkeld L et al (2007) Pediatric tracheotomy: 17 year review. Int $\mathrm{J}$ Pediatr Otorhinolaryngol 7:1829-1835

18. Carr MM, Poje CP, Kingston L et al (2001) Complications in pediatric tracheostomies. Laryngoscope 111:1925-1928

19. Gergin O, Adil EA, Kawai K et al (2016) Indications of pediatric tracheostomy over the last 30 years: has anything changed? Int $\mathrm{J}$ Pediatr Otorhinolaryngol 87:144-147

20. McPherson ML, Shekerdemian L, Goldsworthy M et al (2017) A decade of pediatric tracheostomies: indications, outcomes, and long term prognosis. Pediatr Pulmonol 52:946-953

21. Resen MS, Grønhøj C, Hjuler T (2018) National changes in pediatric tracheotomy epidemiology during 36 years. Eur Arch Otorhinolaryngol 275:803-808

22. Pérez-Ruiz E, Caro P, Pérez-Frías J et al (2012) Paediatric patients with a tracheostomy: a multicentre epidemiological study. Eur Respir J 40:1502-1507

23. Roberts J, Powell J, Begbie J et al (2019) Pediatric tracheostomy: a large single center experience. Laryngoscope 130:375-380

24. Lawrason A, Kavanagh K (2013) Pediatric tracheotomy: are the indications changing? Int J Pediatr Otorhinolaryngol 77:922-925

25. Funamura JL, Durbin-Johnson B, Tollefson TT et al (2014) Pediatric tracheotomy: indications and decannulation outcomes. Laryngoscope 124:1952-1958

26. Funamura JL, Yuen S, Kawai K et al (2017) Characterizing mortality in pediatric tracheostomy patients. Laryngoscope 127:1701-1706

27. Muller RG, Mamidala MP, Smith SH et al (2019) Incidence, epidemiology, and outcomes of pediatric tracheostomy in the United States from 2000 to 2012. Otolaryngol Head Neck Surg 160:332-338

Publisher's Note Springer Nature remains neutral with regard to jurisdictional claims in published maps and institutional affiliations. 